\title{
Electronic cigarettes: where to from here?
}

\author{
Annette J. Theron ${ }^{1}$, Charles Feldman ${ }^{2}$, Guy A. Richards ${ }^{3}$, Gregory R. Tintinger ${ }^{4}$, Ronald Anderson ${ }^{1}$ \\ ${ }^{1}$ Department Immunology and Institute for Cellular and Molecular Medicine, Faculty of Health Sciences, University of Pretoria, Pretoria, South \\ Africa; ${ }^{2}$ Department of Internal Medicine, ${ }^{3}$ Department of Critical Care, Faculty of Health Sciences, University of the Witwatersrand, Johannesburg, \\ South Africa; ${ }^{4}$ Department of Internal Medicine, Steve Biko Academic Hospital and Faculty of Health Sciences, University of Pretoria, Pretoria, \\ South Africa \\ Contributions: (I) Conception and design: All authors; (II) Administrative support: Ms Johanna M. van Wyk; (III) Provision of study materials: None; \\ (IV) Collection and assembly of data: None; (V) Data analysis and interpretation: None; (VI) Manuscript writing: All authors; (VII) Final approval of \\ manuscript: All authors. \\ Correspondence to: Annette J. Theron. Department of Immunology, PO Box 2034, Pretoria 0001, South Africa. Email: atheron@up.ac.za.
}

\begin{abstract}
Although the usage of electronic (e)-cigarettes (EC) and similar devices has gained in popularity as an apparent smoking cessation strategy, serious concerns are emerging in relation to both the efficacy of this strategy, as well as the inappropriate use of these devices. While the comparative safety of e-cigarettes is based on the reasonable contention that the levels of inhaled toxicants present in the aerosols generated by these devices are considerably lower than those present in tobacco smoke, the perception that they are indeed relatively risk-free is being challenged on several fronts. Notwithstanding lack of convincing evidence of efficacy as a superior smoking cessation strategy, foremost among emerging concerns is the increasing use of electronic nicotine-delivery devices by young never-smokers. Other concerns include increasing levels of sophistication in the design and capacity of these devices in relation to nicotine content and delivery, the potential threat of manipulation of the contents of e-liquids, as well as other additives such as illicit drugs and other potentially toxic agents that can be vaporised. These issues, together with the potential risks to respiratory health, specifically "e-cigarette or vaping product use-associated lung injury" represent the major thrusts of this review.
\end{abstract}

Keywords: Smoking cessation; safety; adolescents; nicotine; e-cigarette; or vaping product use associated lung injury

Submitted Feb 18, 2019. Accepted for publication Nov 08, 2019.

doi: $10.21037 /$ jtd.2019.11.82

View this article at: http://dx.doi.org/10.21037/jtd.2019.11.82

\section{Introduction}

The prevalence of tobacco use worldwide is estimated to be in excess of one billion persons (1), while more than 6 million people die each year as a result of cigarette use globally (2). In addition, adult smokers lose an average of 13-15 years of life expectancy related to their smoking habit (3). Tobacco smoke consists of a toxic mix of more than 7,000 chemicals including nicotine, the addictive component of tobacco (4). The chronic inhalation of these toxicants in cigarette smoke has serious health outcomes, causing in particular, cancer, cardiovascular and pulmonary diseases, through mechanisms that include DNA damage, inflammation, and oxidative stress (5). In a more recent report, the Surgeon General also emphasized the risks that smoking, including second-hand smoke, pose for development of non-respiratory tract malignancies such as breast cancer (6).

While many smokers are acutely aware of the health risks posed by their smoking habit, nicotine addiction and psychosocial stressors in particular, make smoking cessation difficult, even for those who are motivated to quit (7). A lucrative industry has therefore blossomed around the development of tools to assist smoking cessation, specifically those based on the use of nicotine replacement products such as nicotine gum, nicotine patches or nicotine spray, 
as well as pharmacological interventions such as the partial nicotinic acetylcholine receptor agonist varenicline and the anti-depressant, bupropion (7). However, the strategy which has generated the greatest enthusiasm and level of uptake among current smokers and impressionable young non-smokers, has been the nicotine-containing electronic (e)-cigarettes (EC). The earliest of these devices, which appeared in Europe and the USA around 2006-2007, were originally of Chinese design and were known as electronic nicotine delivery systems (8).

The current review deals with aspects of EC usage that include their effectiveness in smoking cessation, increasing use by adolescents, the constituents of e-vapors and their potential for harm, specifically adverse effects on respiratory health.

\section{EC}

EC are hand-held devices that simulate the pleasurable sensation and feeling of contentment by those addicted to tobacco smoking by producing a nicotine-containing aerosol, often enhanced by inclusion of flavorants, which are inhaled by the user. Although originally designed as an aid to smoking cessation (9), it is of concern that these devices have also gained popularity among adolescents, many of whom had never used conventional cigarettes (10). The EC consists of a cartridge containing an e-liquid composed mostly of nicotine with or without flavorants, together with the vaporizing propellants, propylene glycol and vegetable glycerine (glycerol). The heating element (a lithium powered atomizer) heats the liquid, converting it into an aerosol that is inhaled by the user. The nicotine content of e-liquid varies, ranging from those that are nicotinefree to concentrations in excess of $20 \mathrm{mg} / \mathrm{mL}$ of liquid (9). Since their emergence in 2007, EC have evolved from cigarette "look-a-likes" to sophisticated and greatly varied, but largely unregulated devices (10). More recently, the JUUL brand of EC that contains a maximum of $59 \mathrm{mg} / \mathrm{mL}$ nicotine, a concentration much higher than that present in standard EC liquids, was introduced to the market in North America (11). Although also available in European countries, the nicotine content of this device is limited to $20 \mathrm{mg} / \mathrm{mL}$ in geographic regions outside of the United States (US).

According to a market research group, the number of EC users increased from 7 million in 2011 to 35 million worldwide in 2016 (12), with the global EC market estimated to be worth USD11.26 billion in 2018 and projected to increase to 18.16 billion by 2024 according to a press release by MarketWatch (13). In the US, the Food and Drug Administration (FDA), following the announcement of the "FDA Deeming Rule" now has authority over all vapor products, enabling regulation of electronic nicotine delivery systems such as EC, which now fall under the category of tobacco products (14).

\section{Nicotine delivery}

Seemingly favorable aspects of EC as an adjunct to smoking cessation were proposed by Farsalinos et al. [2014] who contended that these devices "deal with both the psychobehavioural (through motor simulation and sensory stimulation) and the chemical (through delivery of nicotine) aspects of smoking addiction" (15). These authors found, however, that using EC with an $18 \mathrm{mg} / \mathrm{mL}$ nicotine-containing liquid delivered only one-third to one-fourth of the amount of nicotine delivered by a standard cigarette after 5 minutes of use (15). To achieve maximal delivery of nicotine they advocated the use of new generation EC, which are most efficient with respect to delivery of nicotine, together with the use of liquids containing higher concentrations of nicotine (approximately $50 \mathrm{mg} / \mathrm{mL}$ ) (15).

Schroeder and Hoffman [2014] also stated that "nicotine yields from automated smoking machines suggest that EC deliver less nicotine per puff than traditional cigarettes" (16). This may, however, reflect the experience of the user, with studies indicating that those that are inexperienced are only able to achieve modest nicotine intakes, while experienced users achieve systemic nicotine/cotinine concentrations similar to those produced by smoking of conventional cigarettes (16).

As mentioned above, the JUUL contains higher concentrations of nicotine (11), which is derived from organic nicotine salts extracted from tobacco leaves, rather than from the free-base nicotine contained in standard EC (17). According to Willett et al. [2018], the manufacturer claims that the JUUL provides a nicotine concentration comparable to a traditional cigarette (17).

This, however, is certainly a questionable strategy because attempting to maximize nicotine delivery to these levels will neither alleviate nicotine dependence, nor reduce the harmful acute and chronic effects of nicotine on the cardiovascular system (CVS) and lungs in particular.

\section{Evidence for e-cigarettes as a smoking cessation tool}

Evidence for the use of EC as smoking cessation tools 
remains somewhat unconvincing. One of the marketing ploys, along with "harm reduction", that has been utilized by companies that manufacture vaping products has been that it is an effective smoking cessation strategy. In fact, among Americans attempting to quit, EC are used more often than other FDA-approved cessation aids (18).

The literature has however been relatively inconclusive as to specific success rates using this tool, particularly since the type and design of studies that are used to investigate this issue vary so considerably, For example, EC could be provided by health providers as part of a cessation program with or without control groups, or could be assessed in observational studies in which individuals attempt to stop smoking without controls, or they could be studied in comparison to other cessation aids or placebo. Equally of concern is the number of studies in which the authors have reported links to the tobacco industry or to the manufacturers of vaping products (19). As such, absolute efficacy is, therefore, difficult to evaluate. Although a number of such studies exist, only a few randomized controlled trials (RCTs) have examined their role in smoking cessation.

A Cochrane meta-analysis communicated in 2016 evaluated 24 completed studies available at that time, which included 3 RCTs, only 2 of which were eligible for meta analysis, and 21 cohort studies (20). Two studies comprising 662 participants indicated that EC users were more likely to have quit cigarettes for $\geq 6$ months $v s$. placebo users (RR 2.29, 95\% CI, 1.05 to 4.96; placebo 4\% vs. EC 9\%). The evidence according to GRADE was, however low; in addition, no differences were evident in the one study that compared EC to nicotine patches, which unfortunately also had a very low GRADE rating. Moreover, the analysis did not clarify whether the participants had quit cigarettes in the setting of continuation of use of EC (20).

These findings should also be seen in the light of the much greater success rates achieved with pharmacotherapies. In this context, nicotine-replacement therapy (NRT) and administration of bupropion achieved abstinence rates of $25 \%$ to $26 \%$ at 6 months and $20 \%$ at 1 year respectively, with slightly higher rates for combination therapy, while varenicline had higher quit rates than bupropion and all forms of NRT with $26 \%$ abstinence rates over 24 weeks $(21,22)$.

Another systematic review and meta-analysis, also communicated in 2016, reported opposite results to those of the Cochrane analysis. This analysis encompassed thirty-eight studies, including 20 that had control groups
(15 cohort studies, three cross-sectional studies, and two clinical trials), which were included in random effects meta-analysis and sensitivity analyses. Surprisingly, odds of quitting cigarettes were $28 \%$ lower in the EC groups compared to non-users and the association did not differ irrespective of whether the participants were interested in quitting or not (23).

A more recent observational study evaluating smokers with, or at risk for development of chronic obstructive pulmonary disease (COPD), found that EC use was associated with worse pulmonary-related health outcomes, and did not reduce the frequency of cigarette smoking. The increased harm was difficult to distinguish from that caused by conventional cigarettes, possibly because those that used EC did so because of pre-existing respiratory symptoms (24).

An interesting pragmatic study compared multiple methods of quitting in a large number $(n=6,006)$ of company employees. These included usual care (text messages and educational literature), or usual care plus free cessation aids (NRT or pharmacotherapy), free EC, or the latter two with financial rewards in the form of cash payments or redeemable rewards. The results were disappointing, with 6 -month abstinence rates of $0.1 \%$ with usual care, $0.5 \%$ with free cessation aids, $1.0 \%$ with free EC, $2.0 \%$ with rewards and $2.9 \%$ in the redeemable deposit group (25).

In contrast, in a survey of young adults $(n=1,263)$ that used EC, conducted over 4 years, EC use in those that were highly addicted to cigarettes was associated with a reduction in cigarettes smoked. In those who were not addicted, EC use was associated with an increase in conventional smoking, while in those that used EC as a quitting aid, there was no evidence of benefit (26).

Most of the studies described above originate from the US. However, a more recent study suggests that there may be a greater benefit of EC as a smoking cessation tool in the UK smoking population (27). In this context, 886 adults attending a United Kingdom (UK) smoking cessation clinic were assigned to either a NRT of their choice, provided for up to 3 months, or a refillable EC with one bottle of nicotine e-liquid ( $18 \mathrm{mg} / \mathrm{mL})$, and advised to buy further supplies of the flavor and strength of their choice, all with weekly behavioral support for $\geq 4$ weeks. The 1 year abstinence rate was significantly higher with EC use [18.0\% with EC use $v s .9 .9 \%$ with NRT; relative risk, 1.83 ; $95 \%$ confidence interval $(\mathrm{CI}), 1.30-2.58 ; \mathrm{P}<0.001]$ (27). However, of concern as raised by both the authors and the accompanying editorial (28) in those that successfully abstained for 1 year, $80 \%(63 / 69)$ in the EC group were 
still using their devices vs. 9\% (4 of 44) in the NRT group. In other words, most of the EC group, although not using conventional cigarettes, maintained their nicotine dependence, and consequently, were still exposed to the potential long-term harms of EC $(27,28)$.

These seemingly modest effects of EC on smoking cessation described in most of the aforementioned studies indicate that the available evidence for the efficacy of EC as a cessation strategy is of low quality as proposed by Farsalinos in 2018 (29). This author highlighted several issues with a number of studies. These included the use of outdated and poor quality products that have already been withdrawn, as well as concerns that cohort studies published to date suffer from strong bias, while ever- or current-use of EC was proposed to be a poor measure of assessment efficacy in smoking cessation (29).

Nevertheless, opinions on this issue are somewhat contradictory, particularly in the UK, where there is a belief amongst some experts on tobacco addiction that use of EC, as regulated in the UK, offers benefit to those who wish to quit smoking (30), a contention possibly supported by an annual survey conducted in 2019 in the UK by the polling agency YouGov $(31,32)$. This survey found that the proportion of EC users had risen from $1.7 \%$ in 2012 to $7.1 \%$ in 2019 , which was associated with decreased usage of tobacco products from $19.8 \%$ in 2011 to $14.9 \%$ in 2019 $(31,32)$. Nevertheless, other public health experts in the UK remain cautious in respect of EC usage as a safe smoking cessation strategy (33).

The reasons for the apparent differences with respect to efficacy and safety of EC when comparing the UK and the US in particular remain uncertain, although some experts in the UK have suggested that the US problem is "a cannabis vaping problem" (30). Alternatively, differences in devices and constituents used may play a significant role.

Notwithstanding the UK experience, it is nevertheless evident, that overall, the evidence for the efficacy of EC as a smoking cessation strategy is clearly unconvincing. In addition, in the light of new evidence regarding harm and the potential for EC to function as a "gateway" to nicotine dependence, ongoing evaluation and vigilance are critical.

\section{EC as a "gateway" drug}

Non-smoking adolescents have been using EC increasingly, probably in response to claims regarding safety of EC, as well as successful advertising campaigns promoting the variety of appealing flavors. These trends have been well described in a letter to the New England Fournal of Medicine, analysing and quoting data from "Monitoring the Future", which is a national survey in the USA tracking the use of nicotine products amongst the youth $(34,35)$. These researchers noted that the use of nicotine-containing EC had increased considerably over the periods 2017-2019, predominantly in $12^{\text {th }}$ graders in which there was a $10 \%$ increase, with a corresponding increase of $7.9 \%$ in $10^{\text {th }}$ graders, and $2.6 \%$ in 8 th-graders. There were, however, differences in these trends according to country of origin. Sixteen to 19 years old recruited in 2017 and 2018 from databases in Canada $(n=7,891)$, England $(n=7,897)$, and the US $(n=8,140)$ showed different characteristics (36). Recent use of EC increased in Canada and the US $(\mathrm{P}<0.001$ for all), including among non-smokers and experimental smokers, but with no change in England. Conversely, whereas smoking prevalence increased in Canada $(\mathrm{P}<0.001$ for all measures), there were modest increases in England, and no changes in the US. As in the previous study, the percentage of those that had ever used EC increased in Canada and the US ( $\mathrm{P}<0.01$ for all), but not in England (36).

So, the question is, does the increase in EC use result in an increase in cigarette smoking in adolescents? This issue has been topical since the introduction of EC to the market. A study reported in 2010 confirmed that nicotine exposure could result in nicotine dependence, which was a signal for chronic smoking behaviour (37). Thereafter, numerous studies confirmed that EC use was associated with an increased propensity to smoke cigarettes in subsequent years (38-40).

This contention is supported by a systematic review and meta-analysis of longitudinal studies that included 17,389 adolescents and young adults (14-30 years), which found that the pooled probabilities of cigarette smoking were $23.2 \%$ for those that had ever used EC and $7.2 \%$ if they had never used EC. Following adjustment for known risk factors for cigarette smoking, the pooled odds ratio (OR) for subsequent cigarette smoking was 3.50 (95\% CI, 2.38-5.16) for EC users $v s$. non-users (41).

Another later study involving 1,295 participants aged 16-19 years selected from a national survey, the "Population Assessment of Tobacco and Health", who were assessed according to cigarette smoking, were then correlated with prior use of EC. Smokers who had previously used EC, as opposed to those who had not, were found to have an increased tendency to progress to active smoking measured according to: (I) having smoked $\geq 100$ cigarettes $(19.3 \%$ vs. 9.7\% for those who had previously used EC $v s$. those who 
had not) (or); (II) whether or not they had smoked cigarettes in the previous 30 days (38.8\% vs. $26.6 \%$ ); and (III) whether they were currently established smokers ( $15.6 \%$ vs. $7.1 \%)$. In adjusted models, prior EC use positively predicted current established smoking with an OR of 1.80; (95\% CI: 1.04-3.12) (42).

Given the known harm associated with cigarette smoking and the emerging evidence of harm, possibly by different mechanisms, EC use should be discouraged amongst the youth and similar restrictions to those of cigarette smoking should be enforced, as is the case in many states in the US and in the city of London (43).

\section{Constituents of e-cigarette aerosols}

The widely held belief that the use of EC is safer than traditional cigarettes is based on the fact that these devices do not generate the smoke that is produced by tobacco combustion (44). However, various chemicals and potential toxicants have been found in EC aerosols $(45,46)$. Some of the most commonly encountered of these are listed in Table $1(45,46)$, together with their potentially harmful effects (45-57). As reported by Margham et al. [2016], the concentrations of toxicants are estimated to be $92-99 \%$ less in an $\mathrm{EC}$ aerosol relative to a reference tobacco cigarette, and 9-450 times lower, as described by Goniewicz et al. [2014] $(45,46)$. Although these authors support the view that EC may represent a less harmful alternative to cigarette smoking, they do contend that the presence of toxicants in EC aerosols means that their use is not completely risk-free (46).

Toxicants that have been found in EC aerosols include those belonging to the following groups: carbonyls (e.g., formaldehyde, acetaldehyde and acrolein), alcohols (allyl alcohol, as well as glycerol and propylene glycol), volatile organic compounds (toluene), tobacco-specific nitrosamines, heavy metals and nicotine and related compounds $(45,46)$. Newer generation EC devices have been shown to generate higher levels of aldehydes (e.g., formaldehyde, acetaldehyde and acrolein) because of a higher battery output, although the levels were still lower than those of conventional cigarettes (47). Even at these relatively lower concentrations, however, it is suggested that aldehydes in EC aerosols may cause substantial harm to the CVS (47). At high exposure levels, toluene, tobacco-specific nitrosamines and heavy metals are nephrotoxic, neurotoxic and carcinogenic and also adversely affect the lungs (cough, dyspnea, respiratory failure) $(52,55,57)$.

Potentially damaging flavorants are also present in EC aerosols. A wide variety of these exist, including those that have a berry, cake, candy, fruit or tobacco flavour, with enticing names such as "Cotton Candy" (Vape Dudes), "Peaches N Cream" (Drip), "Euphoria" (Cosmic Fog) etc. (58). Although many of these flavorants are "Generally Recognized As Safe" (GRAS) for food use, they have not been adequately tested for safety when inhaled (59). In this context, toxic agents such as diacetyl, which has been linked to respiratory disease, has been found in a large proportion of sweet flavored e-liquids (58). Other flavorants include 2,3 pentanedione, acetoin, menthol (oxidative, inflammatory), vanillin (respiratory tract irritant, inflammatory) cinnamaldehyde (cytotoxic, oxidative, inflammatory) benzaldehyde (an ingredient in natural fruit-flavored products shown to cause irritation of respiratory airways in cherry flavoured e-liquids), as well as others such as furfural and 5 -hydroxyfurfural, shown to cause irritation of the upper respiratory tract (60).

Although the identities of the EC-derived toxicants which have recently been implicated in the pathogenesis of vaping-associated pulmonary disease, as described in greater detail below, have not been established, putative mechanisms include: (I) respiratory damage "resembling chemical burning" (61) and (II) alterations in lung lipid homeostasis associated with damage to pulmonary surfactants (62). Of additional concern is an increasing awareness that risk-eager vapers appear to be experimenting with lipophilic agents such as vitamin $\mathrm{E}$ acetate, as well as recreational drugs added to e-liquids, including cannabis, cocaine, morphine, 3,4-methylenedioxymethamphetamine ("ecstasy"), temazepam and even fentanyl $(63,64)$.

Furthermore, the finding that EC may be contaminated with microbial toxins is also cause for concern (65). In this study, cartridges and e-liquids sampled from ten top-selling U.S. brands were tested. It was found that $27 \%$ of sampled EC materials contained trace amounts of endotoxin (a microbial product derived from Gram-negative bacteria), while $81 \%$ contained glucan (a component of the fungal cell wall) (65).

\section{Pulmonary Injury related to EC use}

For almost a decade, case reports have appeared in the literature describing various forms of lung disease, apparently associated with the use of EC. These include the following; (I) acute exogenous lipoid pneumonia, which has been attributed to the aspiration of glycerinbased vegetable oils, used in EC to make the visual smoke 


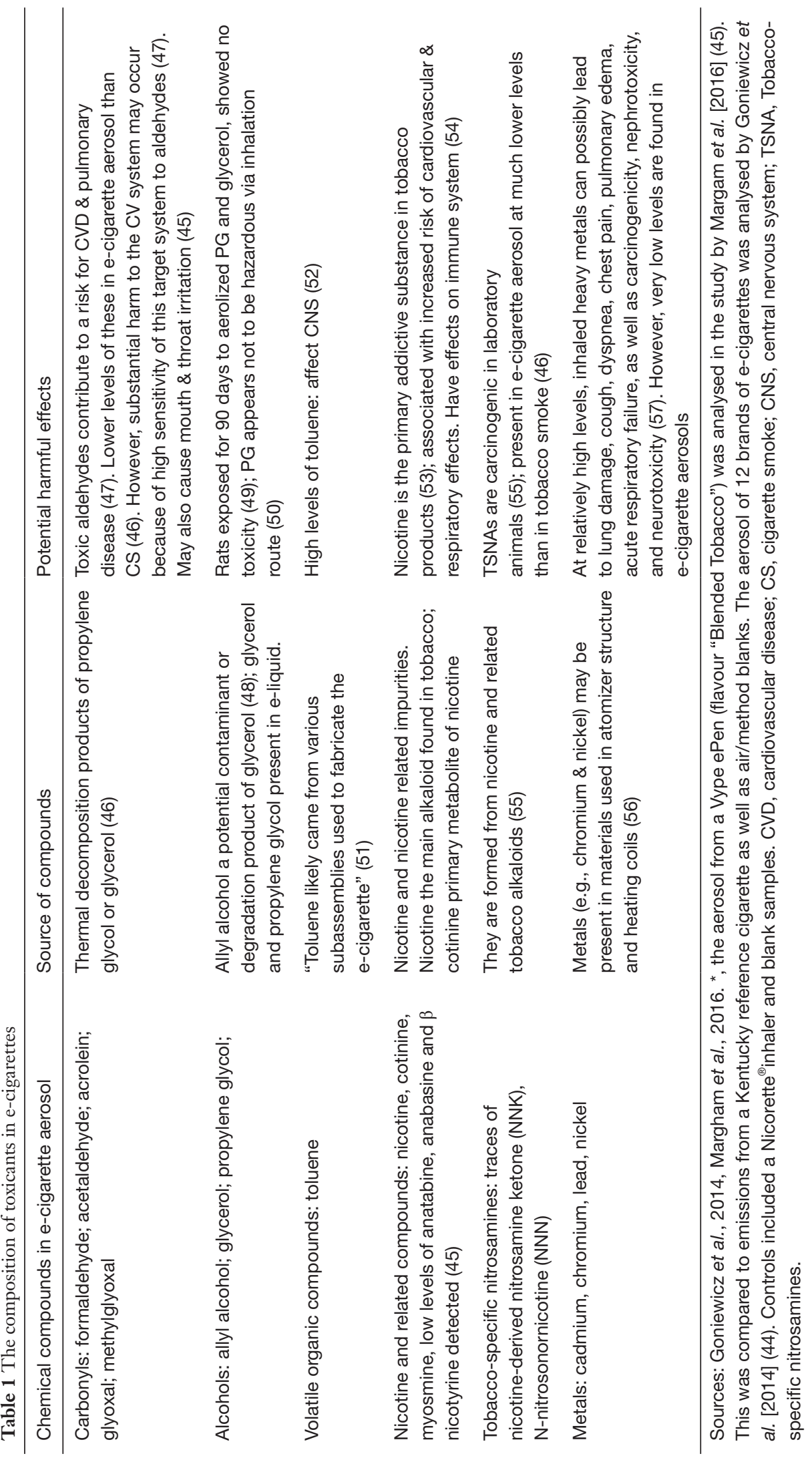


(66-68); (II) acute eosinophilic pneumonia (AEP) (6972); (III) acute hypersensitivity pneumonitis $(73,74)$; (IV) diffuse alveolar haemorrhage (DAH) $(75,76)$; (V) bronchiolitis obliterans organising pneumonia $(77,78)$; (VI) bilateral pneumonia and pleural effusions (79); (VII) respiratory bronchiolitis-associated interstitial lung disease (80); and (VIII) acute lung injury with acute alveolitis (81). Eight of these 15 patients were noted to have developed acute respiratory distress syndrome and/or acute respiratory failure requiring mechanical ventilation. Although not all the case reports had information on treatment, it was noted that corticosteroids were started in 13 of the cases. One of the patients with AEP required veno-venous extracorporeal membrane oxygenation, but recovered, and one of the patients with diffuse alveolar damage (DAD) died despite maximal therapy. More recently, a case series of six young men was reported from Pittsburgh with vaping-associated acute lung injury in order to add that institution's experience and to increase awareness of this syndrome (82).

Interestingly, in the one case report of acute lung injury with acute alveolitis, and one of the case reports of acute lipoid pneumonia, described above, mention was made that lipid-laden macrophages were noted in bronchoalveolar lavage (BAL) fluid $(67,80)$. A further series of six cases of "respiratory syndrome associated with EC" was subsequently reported in the literature (83). The authors indicated that a consistent feature in all was the presence of lipid-laden macrophages seen on oil red O staining of BAL samples, which they mentioned was not attributable to aspiration of exogenous lipoid material, and not characteristic of lipoid pneumonia on computerised tomographic (CT) scans of the chest. Although they indicated that they were uncertain as to the pathophysiological significance of the cells with regard to the etiology of the respiratory syndrome, they suggested these cells may be a potential marker of the condition (83). In this regard, a more recent experimental study indicated that compared with smoke exposure, mice receiving EC vapor for 4 months did not develop inflammation or emphysema; however, they did develop abnormalities in lung lipid homeostasis, irrespective of whether the vapor contained nicotine or not (62). Furthermore, EC-exposed mice developed enhanced lung inflammation and tissue damage when subsequently infected with influenza virus.

With respect to the aforementioned reports, Dinakar and O'Connor published a review article on the health effects of EC in 2016 (84). In their article, they reviewed in detail information that was known at that time with regard to the prevalence and patterns of EC use, their use as a smoking cessation aid, their constituents, and their biological effects in vitro, as well as in experimental animal studies and investigations undertaken in humans. The authors concluded that more research needed to be undertaken with EC in order to clarify their utility as a smoking cessation strategy, to identify possible health risks associated with their use and to make them as safe as possible (84). More recently, Gotts and colleagues have reviewed the evidence for the effects of EC on respiratory health and concluded that there were "measurable adverse biologic effects on organ and cellular health in humans, in animals and in vitro" (85).

On 06 September 2019, the first large series of cases of pulmonary illness in Illinois and Wisconsin in the US related to the use of EC was published (86). From July of that year the Department of Health Services in Wisconsin and the Department of Public Health in Illinois, had received reports of the occurrence of lung disease related to EC use, which necessitated intensive investigation. The authors reviewed the case records of those who had used $\mathrm{EC}$ or related products in the 90 days prior to the onset of symptoms, had pulmonary infiltrates on lung imaging and had no other attributable cause (86). Overall, there were 53 cases, $83 \%$ were male with a median age of 19 years. All patients presented with constitutional symptoms, with $98 \%$ and $81 \%$ presenting with respiratory and gastrointestinal symptoms, respectively. All had bilateral chest infiltrates on imaging. Overall $94 \%$ of cases were hospitalized, $32 \%$ required intubation and ventilation and one patient died. A case definition of so-called "Severe Pulmonary Disease Associated with e-cigarettes" was included in that publication (86), which was issued by the Centers for Disease Control and Prevention (CDC) (87). Interestingly, $84 \%$ of patients reported having used tetrahydrocannabinol (THC) products in EC products, but a wide range of these products and differing devices had been used (86). The same edition of the journal carried a letter including additional cases, as well as images of vaping-associated lung disease with the authors identifying four different patterns, namely, AEP, diffuse alveolar damage, organizing pneumonia and lipoid pneumonia, much like that described in the case reports reviewed above (88). Through clinical and pathological investigations, the authors identified giant cell interstitial pneumonia, hypersensitivity pneumonitis, and DAH (88).

The journal also carried an editorial, which speculated about the possible mechanism of this lung injury (89). The author mentioned that from the information that had been 
gleaned thus far, it did not appear to be of infective origin, but looked as had already been shown in vitro to resemble bronchial epithelium toxicity. In this context, additional investigations are clearly needed to identify the offending toxicants, for example THC and cannabidiol (CBD). Subsequent detailed analysis of histological specimens revealed patterns of acute lung injury "including acute fibrinous pneumonitis, diffuse alveolar damage, or organizing pneumonia, usually bronchiolocentric and accompanied by bronchiolitis" (61). Although histological findings were not specific, foamy macrophages and pneumocyte vacuolization were noted in all the cases and were considered a possible diagnostic clue.

Similar publications were also forthcoming from the CDC, describing the cases, their clinical presentation, radiological imaging, treatment and outcome (90-92). The case definition of this condition, mentioned above, was carried in the early publication from the CDC, while it was also noted that the CDC was coordinating a multi-state investigation (90), working together with the FDA and state and local partners (92). The CDC confirmed that the most commonly reported substances present in the EC devices used by the patients were THC-containing and nicotinecontaining products (92). From the early publication, the CDC recommended that while the investigation was ongoing, and until the definitive cause was identified, that people should consider avoiding these products, while those that continue to use them should monitor themselves closely for development of respiratory and gastrointestinal symptoms, and seek early help for any emerging concerns (90). Furthermore, they indicated that persons using EC should not buy them off the street, not modify them, and not add substances not recommended by the manufacturer (90). They also recommended that youth, young adults, pregnant women, and adults not using tobacco products, should never use EC (90). The most recent update from the CDC was an interim guide for healthcare workers, which provided recommendations for clinical evaluation and management of cases presenting with which has now become known as EVALI (e-cigarette, or vaping, product use associated lung injury) (93).

Other publications, such as that from the American Thoracic Society, and an editorial in the British Medical fournal, have been forthcoming alerting clinicians to this "epidemic" of "severe lung disease" related to vaping $(94,95)$. In addition, a number of daily newspapers around the world have alerted the public to this illness. As a consequence of this escalating public health issue, San Francisco became the first major US jurisdiction to ban the sale of EC as early as June 2019 (96).

As of 22 October 2019, the CDC has reported 1604 lung injury cases from 49 states, the district of Columbia and one US territory, with 34 confirmed deaths (97).

\section{Pro-inflammatory effects of EC}

Cells of the innate immune system, such as neutrophils, alveolar macrophages, as well as structural cells, especially epithelial cells, comprise the first line of the host immune response against invading pathogens and environmental toxicants. However, excessive and prolonged activation of these cells can lead to inflammation-mediated tissue damage and organ dysfunction (98). Mediators of tissue damage released by inflammatory cells that contribute to tissue damage include ROS (reactive oxygen species), proteases, antimicrobial proteins and NETs (neutrophil extracellular traps) as well as pro-inflammatory cytokines such as IL-1 $\beta$, TNF- $\alpha$, IL- 8 , and MCP-2 (99). Importantly, these are key mediators of the inflammatory changes and many of the pathological features seen in the airways of patients with COPD (100). The question arises whether inhalation of EC vapors can also induce similar inflammatory responses in the lower airways. The findings of several publications on this topic are summarized in Table $2(58,101-105)$ and show that exposure of inflammatory cells and airway epithelium to EC or their products may indeed pose the threat of harmful inflammation involving cells of the innate defense system seemingly challenging the concept that EC are healthier alternatives to cigarettes (103). These findings must, however, be viewed against the backdrop of the direct cytotoxic effects of various components of EC vapors (61) on the lungs, possibly exacerbated by pro-inflammatory mechanisms.

Figure 1 is a schematic representation of the potential short- and long-term benefits and harms of EC usage.

\section{Conclusions}

We concede that the introduction of EC seemingly represents a novel and potentially useful smoking cessation strategy. To date, however, only a few studies of current smokers who are seriously committed to smoking cessation, have indicated benefit from the use of EC. Accordingly, the jury remains undecided as to the efficacy of EC in comparison with alternative cessation strategies. Of greatest concern, however, is the potential for abuse of these and 


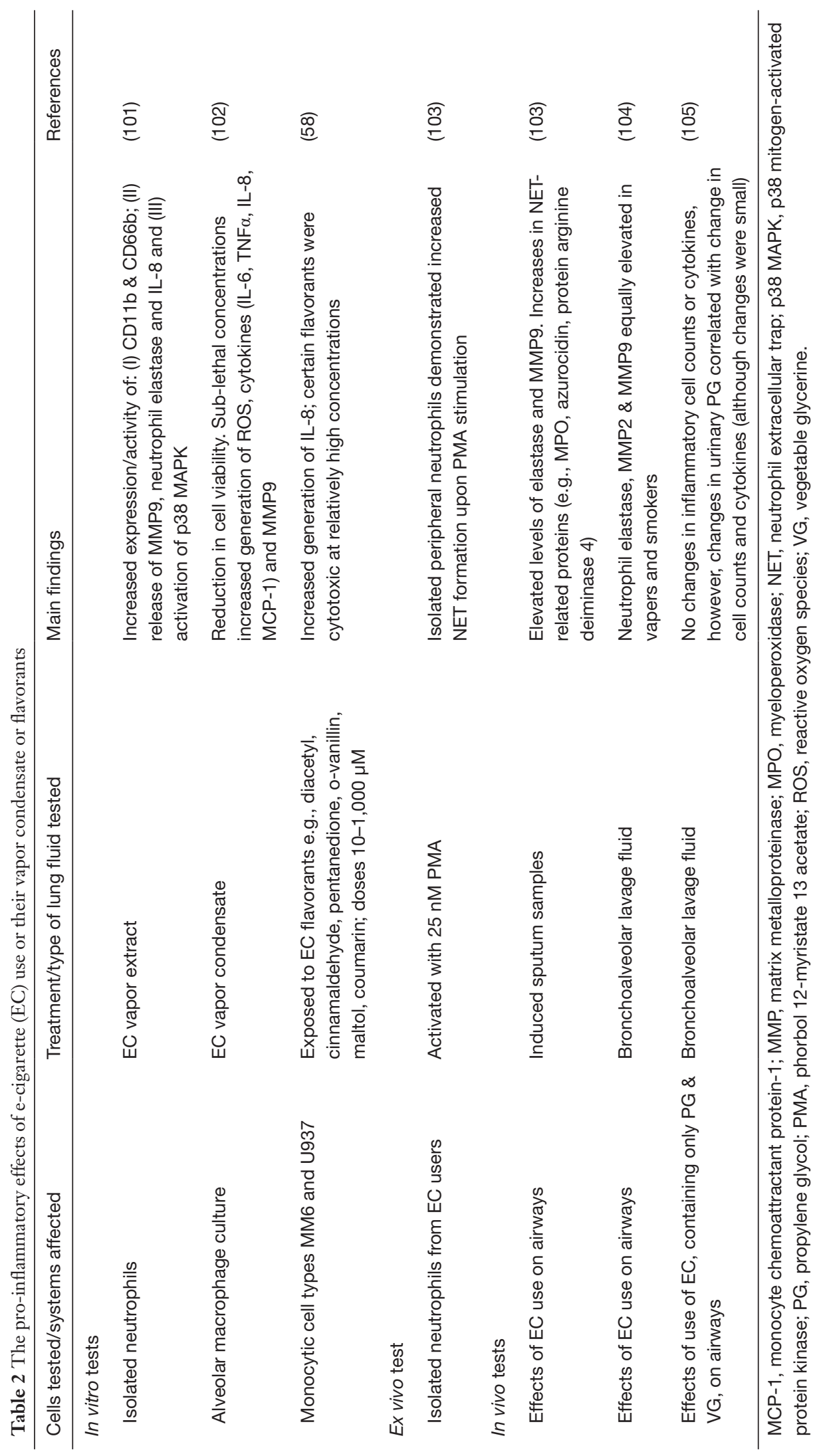




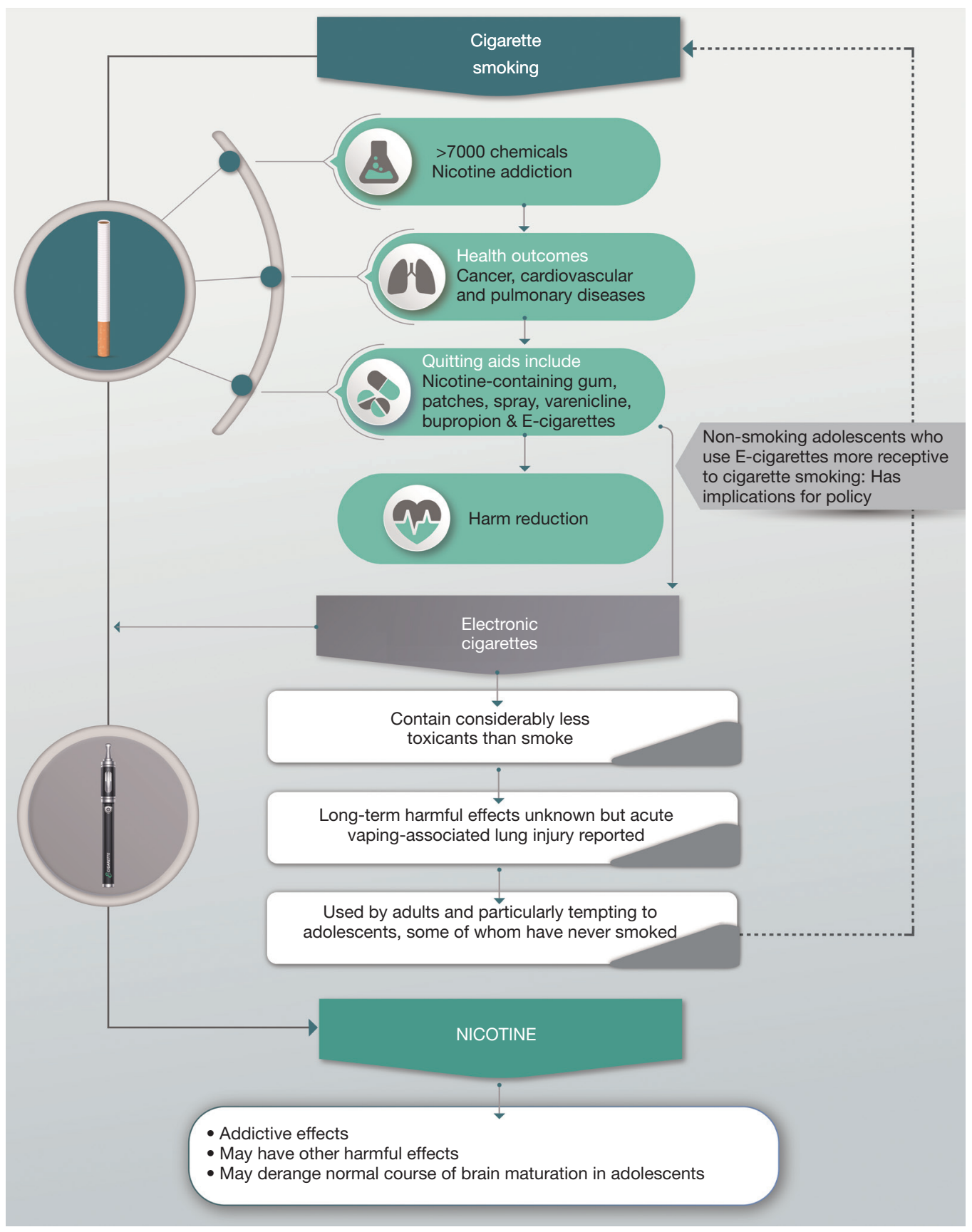

Figure 1 A schematic representation of the potential short- and long-term benefits and harms of EC usage. EC, e- cigarette.

similar types of electronic vaporisers, particularly by, but not limited to, young impressionable never-smokers who appear to be particularly vulnerable to development of vaping-associated serious lung injury. Prevention of experimentation with more sinister types of liquid additives, together with avoidance of prolonged intake of high levels of nicotine appear to represent major challenges to public health authorities. In addition, the possible reasons for the differences in safety and efficacy of EC, as well as the mechanisms of lung-induced injury, in different parts of the world need to be convincingly established to enable more discerning and effective regulation of the vaping habit. 


\section{Acknowledgments}

CF is supported by the National Research Foundation of South Africa.

\section{Footnote}

Conflicts of Interest: The authors have no conflicts of interest to declare.

Ethical Statement: The authors are accountable for all aspects of the work in ensuring that questions related to the accuracy or integrity of any part of the work are appropriately investigated and resolved.

\section{References}

1. WHO. Prevalence of tobacco smoking. 2015. Available online: https://www.who.int/gho/tobacco/use/en/. Accessed 20 September, 2018.

2. Gornall J. Slaying the dragon: how the tobacco industry refuses to die. BMJ 2015;350:h2052.

3. Lee J, Taneja V, Vassallo R. Cigarette smoking and inflammation: cellular and molecular mechanisms. J Dent Res 2012;91:142-9.

4. Benjamin RM. Exposure to tobacco smoke causes immediate damage: a report of the Surgeon General. Public Health Rep 2011;126:158-9.

5. Centers for Disease Control and Prevention (US); 2010. How tobacco smoke causes disease: the biology and behavioural basis for smoking-attributable disease. Available online: https://www.ncbi.nlm.nih.gov/ pubmed/21452462. Accessed 12 October 2018.

6. Glantz SA, Johnson K. The Surgeon General's report on smoking and health 50 years later: breast cancer and the cost of increasing caution. Cancer Epidemiol Biomarkers Prev 2014;23:37-46.

7. van Zyl-Smit RN, Allwood B, Stickells D, et al. South African tobacco smoking cessation clinical practice guideline. S Afr Med J 2013;103:869-76.

8. Pepper JK, Brewer NT. Electronic nicotine delivery system (electronic cigarette) awareness, use, reactions and beliefs: a systematic review. Tob Control 2014;23:375-84.

9. Hartmann-Boyce J, Begh R, Aveyard P. Electronic cigarettes for smoking cessation. BMJ 2018;360:j5543.

10. Jenssen BP, Boykan R. Electronic cigarettes and youth in the United States: a call to action (at the local, national and global levels). Children 2019;6:E30.
11. Jenssen BP, Wilson KM. What is new in electroniccigarettes research? Curr Opin Pediatr 2019;31:262-6.

12. Euromonitor International: Available online: https://blog. euromonitor.com/growth-vapour-products. Accessed 30 October 2019.

13. MarketWatch. Available online: https://www.marketwatch. com/press-release/e-cigarette-market-2019-industrynews-by-revenue-business-growth-top-key-playersupdate-industry-demand-share-global-trend-businessstatistics-and-research-methodology-by-forecastto-2024-2019-06-12. Accessed 30 October 2019.

14. Chowdhury A. Regulation of electronic cigarettes in the United States. IntechOpen 2019. doi:10.5772/ intechopen.86631.

15. Farsalinos KE, Spyrou A, Tsimopoulou K, et al. Nicotine absorption from electronic cigarette use: comparison between first and new-generation devices. Sci Rep 2014;4:4133.

16. Schroeder MJ, Hoffman AC. Electronic cigarettes and nicotine clinical pharmacology. Tob Control 2014;23 Suppl 2:ii30-5.

17. Willett JG, Bennet M, Hair EC, et al. Recognition, use and perceptions of JUUL among youth and young adults. Tob Control 2019;28:115-6.

18. Benmarhnia T, Pierce JP, Leas E, et al. Can e-cigarettes and pharmaceutical aids increase smoking cessation and reduce cigarette consumption? Findings from a nationally representative cohort of American smokers. Am J Epidemiol 2018;187:2397-404.

19. Bals R, Boyd J, Esposito S, et al. Electronic cigarettes: a task force report from the European Respiratory Society. Eur Respir J 2019;53:1801151.

20. Hartmann-Boyce J, McRobbie H, Bullen C, et al. Electronic cigarettes for smoking cessation. Cochrane Database Syst Rev 2016;9:CD010216.

21. Anthenelli RM, Benowitz NL, West R, et al. Neuropsychiatric safety and efficacy of varenicline, bupropion, and nicotine patch in smokers with and without psychiatric disorders (EAGLES): a double-blind, randomised, placebo-controlled clinical trial. Lancet 2016;387:2507-20.

22. Windle SB, Filion KB, Mancini JG, et al. Combination therapies for smoking cessation: a hierarchical bayesian meta-analysis. Am J Prev Med 2016;51:1060-71.

23. Kalkhoran S, Glantz SA. E-cigarettes and smoking cessation in real-world and clinical settings: a systematic review and meta-analysis. Lancet Respir Med 2016;4:116-28. 
24. Bowler RP, Hansel NN, Jacobson S, et al. Electronic cigarette use in US adults at risk for or with COPD: Analysis from two observational cohorts. J Gen Intern Med 2017;32:1315-22.

25. Halpern SD, Harhay MO, Saulsgiver K, et al. A pragmatic trial of e-cigarettes, incentives, and drugs for smoking cessation. N Engl J Med 2018;378:2302-10.

26. Selya AS, Dierker L, Rose JS, et al. The role of nicotine dependence in e-cigarettes' potential for smoking reduction. Nicotine Tob Res 2018;20:1272-7.

27. Hajek P, Phillips-Waller A, Przulj D, et al. A randomized trial of e-cigarettes versus nicotine-replacement therapy. $\mathrm{N}$ Engl J Med 2019;380:629-37.

28. Borrelli B, O'Connor GT. E-cigarettes to assist with smoking cessation. N Engl J Med 2019;380:678-9.

29. Farsalinos K. E-cigarettes: an aid in smoking cessation or new health hazard? Ther Adv Respir Dis 2018;12:1753465817744960.

30. Hawkes N. Vaping: UK experts defend safety in face of US lung injury cases. BMJ 2019;367:16027.

31. YouGov. Smokefree GB. Available online: https://ash. org.uk/wp-content/uploads/2019/09/Use-of-e-cigarettesamong-adults-2019.pdf

32. Kirby T. E-cigarette use in Great Britain. Lancet Respir Med 2019;7:1010.

33. Strick K. E-cigarettes: time to realign our approach? Lancet 2019;394:1297.

34. Miech R, Johnston L, O'Malley PM, et al. Adolescent vaping and nicotine use in 2017-2018 - U.S. national estimates. N Engl J Med 2019;380;192-3.

35. Miech RA, Johnston LD, O'Malley PM, et al. Monitoring the Future: national survey results on drug use, 19752017. Vol. I. Secondary school students. Ann Arbor: University of Michigan Institute for Social Research, 2018. Available online: http://monitoringthefuture.org/ pubs/ monographs/mtf-vol1_2017.pdf

36. Hammond D, Reid JL, Rynard VL, et al. Prevalence of vaping and smoking among adolescents in Canada, England, and the United States: repeat national cross sectional surveys. BMJ 2019;365:12219.

37. Dierker L, Mermelstein R. Early emerging nicotinedependence symptoms: a signal of propensity for chronic smoking behavior in adolescents. J Pediatr 2010;156:818-22.

38. Hammond D, Reid JL, Cole AG, et al. Electronic cigarette use and smoking initiation among youth: a longitudinal cohort study. CMAJ 2017;189:E1328-36.

39. Wills TA, Knight R, Sargent JD, et al. Longitudinal study of e-cigarette use and onset of cigarette smoking among high school students in Hawaii. Tob Control 2017;26:34-9.

40. Watkins SL, Glantz SA, Chaffee BW. Association of noncigarette tobacco product use with future cigarette smoking among youth in the Population Assessment of Tobacco and Health (PATH) study, 2013-2015. JAMA Pediatr 2018;172:181-7.

41. Soneji S, Barrington-Trimis JL, Wills TA, et al. Association between initial use of e-cigarettes and subsequent cigarette smoking among adolescents and young adults. A systematic review and meta-analysis. JAMA Pediatr 2017;171:788-97.

42. Chaffee BW, Watkins SL, Glantz SA. Electronic cigarette use and progression from experimentation to established smoking. Pediatrics 2018;141:e20173594.

43. Loria K. New Restrictions on E-Cigarettes: What You Should Know. Available online: https://www. consumerreports.org/electronic-cigarettes/e-cigaretterestrictions/. Accessed 16 October 2019.

44. Rom O, Pecorelli A, Valacchi G, et al. Are E-cigarettes a safe and good alternative to cigarette smoking? Ann NY Acad Sci 2015;1340:65-74.

45. Goniewicz ML, Knysak J, Gawron M, et al. Levels of selected carcinogens and toxicants in vapour from electronic cigarettes. Tob Control 2014;23:133-9.

46. Margham J, McAdam K, Forster M, et al. Chemical composition of aerosol in e-cigarette: A quantitative comparison with cigarette smoke. Chem Res Toxicol 2016;29:1662-78.

47. Ogunwale MA, Li M, Raju MVR, et al. Aldehyde detection in electronic cigarette aerosols. ACS Omega 2017;2:1207-14.

48. Liu X, Joza P, Rickert WA. Determination of allyl alcohol in electronic cigarette (e-cig) aerosol and liquids using gas chromatography-mass spectrometry. TSRC, Tob Sci Res Conf 2015;69, abstract 50. Available online: https:// www.coresta.org/abstracts/determination-allyl-alcoholelectronic-cigarette-e-cig-aerosol-and-liquids-using-gas. Accessed 31 October 2019.

49. Phillips B, Titz B, Kogel U, et al. Toxicity of the main electronic cigarette components, propylene glycol, glycerine, and nicotine, in Sprague-Dawley rats in a 90day OECD inhalation study complemented by molecular endpoints. Food Chem Toxicol 2017;109:315-32.

50. Cotta KI, Stephen CD, Mohammad NU. A review on the safety of inhalation of propylene glycol in e-cigarettes. Glob J Pharmaceu Sci 2017;2:555584.

51. Lauterbach J. Is e-cigarette industry the biggest enemy of the e-cigarette today? A reply. Ecigarette Research 2014, 19 
March. Available online: http://www.ecigarette-research. com/web/index.php/2013-04-07-09-50-07/2014/159-ecig-jl. Accessed 16 April 2018.

52. ATSDR. Agency for Toxic Substances \& Disease Registry. Public Health Statement for toluene. Available online: https://www.atsdr.cdc.gov/phs/phs.asp?id=159\&tid=29. Last Update: January 21, 2015. Accessed 18 April 2018.

53. Benowitz NL. Nicotine addiction. N Engl J Med 2010;362:2295-303.

54. Mishra A, Chaturvedi P, Datta S, et al. Harmful effects of nicotine. Indian J Med Paediatr Oncol 2015;36:24-31.

55. Hecht SS, Tricker AR. Nitrosamines derived from nicotine and other tobacco alkaloids. In Analytical Determination of Nicotine and Related Compounds and Their Metabolites, Gorrod JW, Jacob P III (eds). Elsevier: Amsterdam, 1999;421. https://doi.org/10.1016/B978044450095-3/50012-7

56. Farsalinos KE, Voudris V, Poulas K. Are metals emitted from electronic cigarettes a reason for health concern? A risk-assessment analysis of currently available literature. Int J Environ Res Public Health 2015;12:5215-32.

57. Zhang G, Wang Z, Zhang K, et al. Safety assessment of electronic cigarettes and their relationship with cardiovascular disease. Int J Environ Res Public Health 2018;15:E75.

58. Muthumalage T, Prinz M, Ansah KO, et al. Inflammatory and oxidative responses induced by exposure to commonly used e-cigarette flavouring chemicals and flavoured e-liquids without nicotine. Front Physiol 2018;8:1130.

59. Farsalinos KE, Kistler KA, Gillman G, et al. Evaluation of electronic cigarette liquids and aerosol for the presence of selected inhalation toxins. Nicotine Tob Res 2015;17:168-74.

60. Kaur G, Muthumalage T, Rahman I. Mechanisms of toxicity and biomarkers of flavouring and flavour enhancing chemicals in emerging tobacco and non-tobacco products. Toxicol Lett 2018;288:143-55.

61. Butt YM, Smith ML, Tazelaar HD, et al. Pathology of vaping-associated lung injury. N Engl J Med 2019;381:1780-1.

62. Madison MC, Landers CT, Gu BH, et al. Electronic cigarettes disrupt lung lipd homeostasis and innate immunity independent of nicotine. J Clin Invest 2019;129:4290-304.

63. Jones I. Vapers experimenting with illegal drugs bought on the dark web. New Scientist. Technology News 2016. Available online: https://www.newscientist.com/ article/mg23231045-800-vapers-experimenting-withillegal-drugs-bought -on the-dark-web//. Accessed 2 October 2018.
64. Varlet V, Concha-Lozano N, Berthet A et al. Drug vaping applied to cannabis: Is "Cannavaping" a therapeutic alternative to marijuana? Sci Rep 2016;6:25599.

65. Lee M-S, Allen JG, Christiani DC. Endotoxin and $(1 \rightarrow 3)-\beta$-DGlucan contamination in electronic cigarette products sold in the United States. Environ Health Perspect 2019;127:047008.

66. McCauley L, Markin C, Hosmer D. An unexpected consequence of electronic cigarette use. Chest 2012;141:1110-3.

67. Modi S, Sangani R, Alhajhusain A. Acute lipoid pneumonia secondary to E-cigarettes use: An unlikely replacement for cigarettes. Chest 2015;148:382A.

68. Viswam D, Trotter S, Burge S, et al. Respiratory failure caused by lipoid pneumonia from vaping e-cigarettes. BMJ Case Rep 2018. doi: 10.1136/bcr-2018-224350.

69. Thota D, Latham E. Case report of electronic cigarettes possibly associated with eosinophilic pneumonitis in a previously healthy active-duty sailor. J Emerg Med 2014;47:15-7.

70. Kamada T, Yamashita Y, Tomioka H. Acute eosinophilic pneumonia following heat-not-burn cigarette smoking. Respirol Case Rep 2016;4:e00190.

71. Aokage T, Tsukahara K, Fukuda Y, et al. Heat-not-burn cigarettes induce fulminant acute eosinophilic pneumonia requiring extracorporeal membrane oxygenation. Respir Med Case Rep 2018;26:87-90.

72. Arter ZL, Wiggins A, Hudspath C, et al. Acute eosinophilic pneumonia following electronic cigarette use. Respir Med Case Rep 2019;27:100825.

73. Sommerfeld CG, Weiner DJ, Nowalk A, et al. Hypersensitivity pneumonitis and acute respiratory distress syndrome from E-cigarette use. Pediatrics 2018;141:e20163927.

74. Atkins G, Drescher F. Acute inhalational lung injury related to the use of electronic nicotine delivery system (ENDS). Chest 2015;148:83A.

75. Long JL, Devabhaktuni S, Hadique S, et al. Diffuse alveolar hemorrhage due to electronic cigarette use. Am J Respir Crit Care Med 2016;193:A1862.

76. Agustin M, Yamamoto M, Cabrera F, et al. Diffuse alveolar hemorrhage induced by vaping. Case Rep Pulmonol 2018;2018:9724530.

77. Khan MS, Khateeb F, Akhtar J, et al. Organizing pneumonia related to electronic cigarette use: A case report and review of literature. Clin Respir J 2018:12:1295-9.

78. Mantilla RD, Darnell RT, Sofi U. Vapor lung: bronchiolitis obliterans organizing pneumonia (boop) in 
patients with E-cigarette use. Am J Respir Crit Care Med 2016;193:A6513.

79. Flower M, Nandakumar L, Singh M, et al. Respiratory bronchiolitis-associated interstitial lung disease secondary to electronic nicotine delivery system use confirmed with open lung biopsy. Respirol Case Rep 2017;5:e00230.

80. Moore K, Young H II, Ryan MF. Bilateral pneumonia and pleural effusions subsequent to electronic cigarette use. Open J Emerg Med 2015;3:18-22.

81. Itoh M, Aoshiba K, Herai Y, et al. Lung injury associated with electronic cigarettes inhalation diagnosed by transbronchial lung biopsy. Respirol Case Rep 2017;6:e00282.

82. Triantafyllou GA, Tiberio PJ, Zou RH, et al. VapingAssociated Acute Lung Injury: A Case Series. Am J Respir Crit Care Med 2019. [Epub ahead of print]

83. Maddock SD, Cirulis MM, Callahan SJ, et al. Pulmonary lipid-laden macrophages and vaping. N Engl J Med 2019;381:1488-9.

84. Dinakar C, O'Connor GT. The health effects of electronic cigarettes. N Engl J Med 2016;375:1372-81.

85. Gotts JE, Jordt SE, McConnell R, et al. What are the respiratory effects of e-cigarettes. BMJ 2019;366:15275.

86. Layden JE, Ghinai I, Pray I, et al. Pulmonary illness related to E-cigarette use in Illinois and Wisconsin preliminary report. N Engl J Med 2019. [Epub ahead of print]

87. 2019 Lung Injury Surveillance Case Definition (CDC) September 18, 2019. Available online: https://www.cdc. gov/lunginjury. Accessed 2 October, 2019.

88. Henry TS, Kanne JP, Kligerman SJ, et al. Imaging of vaping-associated lung disease. $\mathrm{N}$ Engl J Med 2019;381:1486-7.

89. Christiani DC. Vaping-induced lung injury. N Engl J Med 2019. [Epub ahead of print].

90. Schier JG, Meiman JG, Layden J, et al. Severe pulmonary disease associated with electronic-cigarette-produce use interim guidance. MMWR 2019;68:787-90.

91. Davidson K, Brancato A, Heerderks P, et al. Outbreak of electronic-cigarette-associated acute lipoid pneumonia - North Carolina, July - August 2019. MMWR Morb Mortal Wkly Rep 2019;68:784-6.

92. Perrine CG, Pickens CM, Boehmer TK, et al. Characteristics of a multistate outbreak of lung injury associated with E-cigarette use, or vaping - United States, 2019. MMWR Morb Mortal Wkly Rep 2019;68:860-4.

93. Siegel DA, Jatlaoui TC, Koumans EH, et al. Update: Interim guidance for health care providers evaluating and caring for patients with suspected e-cigarette, or vaping, product use associated lung injury — United States, October 2019. MMWR 2019;68:919-27.

94. Carlos WG, Alexander LEC, Gross JE, et al. Vaping associated pulmonary illness (VAPI). Am J Respir Crit Care Med 2019;200:13-4.

95. Hammond D. Outbreak of pulmonary diseases linked to vaping. BMJ 2019;366:15445.

96. Koh HK, Douglas CE. The San Francisco ban and the future of e-cigarettes. JAMA 2019;322:1540-1.

97. Centers for Disease Control and Prevention. Outbreak of lung injury associated with e-cigarette use, or vaping. Updated October 24, 2019. Available online: https://www. cdc.gov/tobacco/basic_information/e-cigarettes/severelung-disease.html. Accessed 31 October 2019.

98. Mortaz E, Alipoor SD, Adcock IM, et al. Update on neutrophil function in severe inflammation. Front Immunol 2018;9:2171.

99. Wang J. Neutrophils in tissue injury and repair. Cell and Tissue Research 2018;371:531-9.

100.Jasper AE, McIver WJ, Sapey E, et al. Understanding the role of neutrophils in chronic inflammatory airway disease. F1000Res 2019. doi:10.12688/f1000research.18411.1.

101. Higham A, Rattray NJW, Dewhurst JA, et al. Electronic cigarette exposure triggers neutrophil inflammatory responses. Respir Res 2016;17:56.

102. Scott A, Lugg ST, Aldridge K, et al. Pro-inflammatory effects of e-cigarette vapour condensate on human alveolar macrophages. Thorax 2018;73:1161-9.

103. Reidel B, Radicioni G, Clapp PW, et al. E-cigarette use causes a unique innate immune response in the lung, involving increased neutrophilic activation and altered mucin secretion. Am J Respir Crit Care Med 2018;197:492-501.

104. Ghosh A, Coakley RD, Ghio AJ, et al. Chronic e-cigarette use increases neutrophil elastase and matrix metalloprotease levels in the lung. Am J Respir Crit Care Med 2019. [Epub ahead of print]

105. Song MA, Reisinger SA, Freudenheim JL et al. Effects of electronic cigarette constituents on the human lung: A pilot clinical trial. Cancer Prev Res (Phila) 2019. doi:10.1158/1940-6207.

Cite this article as: Theron AJ, Feldman C, Richards GA, Tintinger GR, Anderson R. Electronic cigarettes: where to from here? J Thorac Dis 2019;11(12):5572-5585. doi: 10.21037/ jtd.2019.11.82 